\title{
Las investigaciones sobre educación legal universitaria en la Argentina: diagnósticos y perspectivas
}

\section{Research on university legal education in Argentina: diagnostic and perspectives}

\begin{abstract}
Nancy Cardinaux ${ }^{1}$
Resumen: Este artículo se plantea dos objetivos. En primer lugar, presentar los principales puntos de convergencia a los que han arribado las líneas de investigación empírica que se han desarrollado durante la última década en la Argentina sobre enseñanza del derecho a nivel universitario. En particular, se abordan las prácticas áulicas y las representaciones de alumnos y docentes. En segundo lugar, se focaliza sobre las concepciones del derecho y su relación con las estrategias montadas para su enseñanza; con ese norte, se genera una tipología que permite criticar las prácticas de enseñanza predominantes y tal vez ensayar otras que nutran aquellas concepciones del derecho de las que cada docente parte.
\end{abstract}

Palabras clave: investigación-enseñanza-derecho-universidad-Argentina

\begin{abstract}
This paper aims two goals. Firstly, it is sought to present the main common points of the empirical reached research lines on teaching Law at University level, which have been developed in Argentina over the last decade. Specifically, classroom practices and representations of students and teachers are addressed in this article. Secondly, it is focused on the conceptions of Law and its relation to the strategies involved in its teaching. From this point, it is generated a typology that allows to criticize the prevailing teaching practices and, maybe, to try doing others ones that support to those starting conceptions of the law teachers.
\end{abstract}

Keywords: research- teaching- law- University-Argentina

\section{Introducción: La inserción de la carrera de derecho en el sistema universitario argentino}

Las carreras de abogacía convocan a una porción importante de la población de estudiantes universitarios argentinos. De acuerdo al último anuario publicado por la Secretaría de Políticas Universitarias $^{2}$, correspondiente al año 2010, el número de estudiantes de derecho en el país era de 208.937 sobre una población universitaria total de 1.718 .507 alumnos. El 12,15\% de esos estudiantes está siguiendo pues la carrera de abogacía. ${ }^{3} \mathrm{Si}$ tomamos el número de inscriptos en la carrera de derecho y de egresados de la misma, veremos que los primeros alcanzan el 10,82\% y los segundos el $14,08 \%$.

\footnotetext{
${ }^{1}$ Abogada, Especialista en Ciencias Sociales y en Sociología Jurídica y Doctora de la Universidad de Buenos Aires. Investigadora del Consejo Nacional de Investigaciones Científicas y Técnicas de la República Argentina, Profesora Regular de la Universidad de Buenos Aires y de la Universidad Nacional de La Plata.

${ }^{2}$ La SPU es un organismo dependiente del Ministerio de Educación de la Nación.

${ }^{3}$ Esta cifra sólo es superada por los estudiantes de ciencias económicas aunque en este caso la SPU no desagrega las carreras de licenciaturas en ciencias económicas, licenciaturas en economía y licenciaturas en administración de empresas.
} 
De las 88 universidades argentinas, 55 cuentan con una carrera de Derecho y, si comparamos la presencia de carreras de derecho en universidades públicas y privadas, observaremos que es mayor en estas últimas: la carrera de derecho forma parte de la oferta del $73 \%$ de las universidades privadas y del $54 \%$ de las universidades públicas. Las principales razones para esta incorporación tan marcada de la carrera de derecho en las universidades privadas son: la magnitud de la potencial matrícula y el bajo costo asignado a esta carrera (tipificada como de "tiza y pizarrón") con respecto a otras carreras. Sin embargo, dada las distintas dimensiones del sistema público y privado de educación universitaria (el primero concentraba, en 2010, 1.366.237 alumnos mientras que el segundo se reducía a 352.270), evidentemente el mayor número de alumnos de derecho está estudiando en universidades públicas: 145.302 mientras que las universidades privadas concentran 63.635 alumnos. Es decir que el 69,54\% de los estudiantes de derecho están matriculados en universidades públicas mientas que el 30,46\% estudian en alguna universidad privada.

Un dato muy importante, y que nos preocupa en todo el sistema educativo, es el abandono de los estudios, que en el ámbito universitario en general alcanza cuotas de más del $60 \%$. Aunque doy por sentada la importancia de un sistema de ingreso irrestricto, sin exámenes ni cupos, está claro que este dato nos tiene que ocupar. Tal vez sea atribuible a la crisis de legitimidad que, de acuerdo a Santos, atraviesan nuestros sistemas universitarios y está provocada "por el hecho de haber dejado de ser la universidad una institución consensual, frente a la contradicción entre la jerarquización de los saberes especializados de un lado, a través de las restricciones del acceso y certificación de las competencias, y de otro lado, por las exigencias sociales y políticas de la democratización de las universidad y de la reivindicación de la igualdad de oportunidades para los hijos de las clases populares"4. Es posible que esta sea una de las razones pero es un deber básico interrogarnos y ocuparnos de este enorme número de estudiantes que abandonan sus estudios porque estamos en plena expansión del sistema universitario (la muestra más evidente es la creación de nuevas universidades nacionales) pero, si no trabajamos sobre los factores de expulsión, es probable que el número de egresados se mantenga estable o muy por debajo del crecimiento de la tasa de matriculación.

Ahora bien, en relación a las facultades de derecho en particular, las investigaciones con las que contamos acerca de las razones por las que un número tan alto de los alumnos elige la carrera de abogacía entroncan con las razones históricas, entre las que se destaca la multiplicidad de roles sociales prestigiosos para los que acredita, pero a ellas se suma que es una de las carreras cuya demanda laboral ha aumentado aún en períodos de profunda crisis. Bergoglio y Carballo $^{5}$, en una investigación sobre inserción laboral de los abogados en base a datos de la Encuesta Permanente de Hogares ${ }^{6}$ de 2002, concluían que la tasa de desocupación de los abogados era menor que la del resto de las profesiones ( $2 \%$ entre aquellos y $4,5 \%$ para los profesionales en general) y marcaban dos tendencias que sin duda se han consolidado en la última década: la reducción del número de abogados independientes en beneficio del empleo asalariado en grandes empresas jurídicas, y la inserción mayor (y más buscada)

\footnotetext{
${ }^{4}$ SOUSA SANTOS, Boaventura de, La universidad en el Siglo XXI. Para una reforma democrática y emancipadora de la universidad, 2005, pp. 15-16

${ }^{5}$ BERGOGLIO, María Inés y CARBALLO, Jerónimo, "Segmentación en la profesión jurídica: cambios ocupacionales de los abogados argentinos. 1995-2003”, 2005, pp. 201-222.

${ }^{6}$ Encuesta realizada dos veces por año por el INDEC (Instituto Nacional de Estadísticas y Censos) y cuyos datos fueron desagregados para la investigación que estamos reseñando.
} 
en el ámbito público que en el privado como consecuencia de la expansión de la administración de justicia que, en la Argentina, parece no haber llegado todavía a su techo ${ }^{7}$. La administración de justicia, sobre todo en los escalafones más bajos ofrece tres condiciones que la tornan mucho más atractiva para los jóvenes abogados: condiciones formales de contratación, estabilidad y mejores sueldos. Tampoco puede obviarse que la carrera de abogacía es una de las que mayores posibilidades brinda para estudiantes que comparten trabajo y estudio. En nuestro país, y aún en las universidades públicas, las carreras están fuertemente segmentadas en este punto: hay carreras que exigen dedicación exclusiva (ciencias médicas, algunas ingenierías, ciencias físicas y naturales, etc.) mientras que las currículas de otras, sus bandas horarias, su régimen de regularidad y su sistema de cursos y exámenes permiten que se combinen con un trabajo de alta o media carga horaria.

En definitiva, estoy refiriéndome a una carrera que ha concentrado una alta porción de la población de estudiantes universitarios argentinos, tanto en las universidades de gestión pública como privada y que, desde hace décadas, ha sido objeto de estudio. Nos dedicaremos a continuación a mencionar a quiénes han realizado esas investigaciones para luego relevar qué aspectos de los estudios universitarios de derecho han concitado mayor atención por parte de la agenda de la investigación educativa. Focalizaremos sobre el formalismo y la clase magistral, por un lado, y la tensión entre enseñanza teórica y práctica. Por último, presentaré una hipótesis de trabajo que relaciona las concepciones del derecho con las estrategias de enseñanza del derecho, con el objetivo de generar una metodología de análisis que sirva como base a futuras investigaciones sobre pedagogía jurídica universitaria.

\section{Los equipos de investigación sobre educación legal en la Argentina}

En el discurso jurídico, articulado en torno a prescripciones, es lógico que encontremos muchos más mensajes acerca de cómo debe ser la educación jurídica que sobre cómo efectivamente es. Desde luego doy por sentado que algún horizonte regulativo orienta cualquier diagnóstico pero me interesa partir aquí desde una perspectiva sociológica que dé cuenta de cómo es la educación jurídica universitaria en la Argentina. Para hacerlo me basaré fundamentalmente en dos fuentes: en primer lugar, tomaré como referencia la producción publicada en Academia, la Revista sobre enseñanza del derecho publicada por la Facultad de Derecho de la Universidad de Buenos Aires. Esta Facultad concentra la mayor parte de los estudiantes del país y desde hace diez años sostiene esta publicación en la que conviven las voces de los clásicos, resultados de investigaciones empíricas y líneas de desarrollo teórico. En segundo lugar, tomaré los resultados de las comisiones de enseñanza jurídica que desde hace 13 años vienen desarrollándose en los Congresos Nacionales de Sociología Jurídica que anualmente realizamos (durante el mes de noviembre) en alguna Universidad nacional del país. Las ponencias presentadas a esas comisiones dan cuenta de los resultados de las principales líneas de investigación sobre la temática en las facultades de derecho del país desde la perspectiva sociológica. Estas dos fuentes se entrecruzan, por cuanto un número importante de dichas ponencias se ha convertido luego en un artículo de Academia. Como en parte he sido responsable de esa selección, varios de los trabajos que aquí tomaré como fuente fueron ponencias más tarde publicadas en Academia y de ahí las referenciaré. Es importante señalar aquí que en ocasión de la celebración del décimo aniversario de los congresos de sociología jurídica, se emprendió la tarea de construir una

\footnotetext{
${ }^{7}$ Esa expansión de la administración de justicia está fuertemente relacionada con el proceso de democratización que ha generado nuevos sujetos y nuevos derechos.
} 
suerte de estado del arte de cada comisión del congreso. El correspondiente a la comisión de educación jurídica permite avizorar cuáles son las principales continuidades y también las ausencias más notorias en la investigación sociojurídica sobre la pedagogía del derecho ${ }^{8}$.

No considero como referencia investigaciones sobre educación legal universitaria realizadas en el marco de las facultades que incorporan carreras de educación o pedagogía, porque no hay en el país equipos de investigación de tales inserciones que se hayan dedicado con persistencia al tema. Sí han tomado como objetivo de investigación la educación legal en los niveles inicial, primario y, en menor medida, en la escuela media ${ }^{9}$. Es una carencia importante no tanto por la ausencia de diagnósticos, que se han desarrollado en el área de las facultades de derecho por equipos que cuentan entre sus integrantes con licenciados en educación, sino por la falta de desarrollo de una didáctica jurídica. ${ }^{10}$ Entiendo que una didáctica jurídica universitaria puede tener hoy a las carreras docentes de las facultades de derecho como sus principales usinas pero, si lo hay, es apenas embrionario. ${ }^{11}$

\section{Una pareja perfecta: el formalismo y la clase magistral}

La concepción formalista, largamente criticada tanto en la enseñanza como en la aplicación del derecho, queda evidenciada en los múltiples trabajos de campo realizados en las aulas de facultades de derecho de nuestro país. Y la clase magistral resulta, entre las distintas estrategias de enseñanza, la mayoritariamente (cuando no exclusivamente) adoptada por los docentes de derecho. Formalismo y clase magistral conforman una pareja perfecta por cuanto ese derecho que se dice, se relata, se expresa, se declama, requiere un orador que lo autorice fuertemente y la estrategia didáctica que mejor se amolda a esa centralidad del orador es la clase magistral. Pero veamos primero algunos registros con que contamos sobre formalismo para luego pasar a tratar la clase magistral.

\section{Formalismo}

Lista y Begalá realizaron un experimento con alumnos avanzados de la carrera de abogacía de la Universidad Nacional de Córdoba, a los que presentaron una serie de consignas sobre cuatro casos conflictivos. Al relevar las conclusiones de ese experimento, dicen los investigadores: "En sus trabajos, los alumnos evidencian con mucha claridad una marcada tendencia a enfatizar la vigencia de

\footnotetext{
${ }^{8}$ GONZÁLEZ, Manuela et.al., "La formación de los abogados y la formación jurídica en Argentina", 2011, pp. 279-334

${ }^{99}$ En general estas investigaciones abordan el desarrollo de nociones jurídicas por parte de los niños y adolescentes y, en general, se realizan en el contexto de las escuelas tomando como base entrevistas, cuadernos de clase, manuales escolares, diseños y desarrollos curriculares, etc. aunque raramente abordan de manera central las estrategias de enseñanza del derecho en las escuelas.

${ }^{10}$ Sin desconocer las discusiones que, desde la didáctica general, se han dado acerca de las potencialidades y límites que las didácticas especiales tienen, entiendo que la especificidad del derecho como objeto de enseñanza y aprendizaje y su centralidad en el marco de la formación ciudadana en todos los niveles merece el desarrollo de algunas líneas de indagación teórica acerca de cómo mejorar su enseñanza. Y es posible que, si bien los objetivos de la enseñanza legal en el nivel universitario son otros, esos desarrollos didácticos podrían tener un impacto positivo sobre este nivel.

${ }^{11}$ Hace siete años terminamos una investigación que codirigí con Laura Clérico sobre la historia de la carrera docente de la Facultad de Derecho de la Universidad de Buenos Aires, cuyos resultados no mostraban que tal didáctica específica estuviera en vías de desarrollarse. Han pasado varios años y en los últimos dicha carrera se ha reformulado pero, sabiendo que la consolidación de una didáctica lleva mucho tiempo, es probable que, aún cuando la tarea haya comenzado, seguramente hace falta tiempo todavía para comenzar a ver los frutos. Los resultados de aquella investigación se pueden consultar en: CARDINAUX, Nancy et.al, De cursos y de formaciones docentes, 2005, pp. 121-157.
} 
la ley más allá de su efectividad. Las estrategias de solución se limitan a la búsqueda del derecho aplicable. Encontrar la norma que consagra el derecho vulnerado o que castiga la conducta que lo vulnera es entendido como solución...La mayoría de las soluciones propuestas consisten en la aplicación del derecho, sin analizar cuál es la contribución concreta que la norma realiza para satisfacer los intereses de la parte que los alumnos pretenden representar. Confunden invocación del derecho y argumentación con estrategia, tienen habilidad para invocar el derecho en forma coherente, pero en muchos casos no identifican la vía para hacerlo efectivo. La mera invocación del derecho en sí genera orden, produce un resultado, una solución; su vigencia como orden normativo parece ser suficiente para poner fin a los conflictos" $"$.

La centralidad que ocupa el derecho desgajado tanto de sus condiciones de producción como de su contexto de aplicación es marcada por ésta como por todas las investigaciones áulicas que se han llevado a cabo en nuestras facultades de derecho. Por supuesto esa centralidad también está presente en los discursos institucionales; el registro de los debates sobre cambios de planes de estudio de las carreras de abogacía que venimos siguiendo desde hace años da cuenta de que la principal preocupación consiste en que tales planes atrapen la totalidad de lo que se considera derecho desde una perspectiva formalista. Un documento oficial de la Facultad de Ciencias Jurídicas y Sociales de la Universidad Nacional de La Plata, elaborado para una frustrada reforma curricular, da muestra de esa pretensión de atrapar todas las fuentes del derecho en los contenidos de la carrera:

(E)n cinco años de carrera de grado y ante el fenómeno del crecimiento exponencial del derecho que debe enseñarse (multiplicación de leyes, decretos, resoluciones, proliferación de la doctrina y las decisiones jurisprudenciales, normativas transnacionales, etc.), y las correlativas exigencias de los ejercicios profesionales (abogacía, magistraturas, etc.), el gran desafío afinca en conformar un plan abarcador de los contenidos esenciales y que, al mismo tiempo, brinde a los futuros abogados conocimientos, siquiera elementales, de los nuevos desarrollos y disciplinas (derecho ambiental, de consumidores y derechos colectivos en general, derecho bancario, seguros, comunicaciones, etc.), propios de las especializaciones y maestrías ${ }^{13}$.

Este párrafo encierra una síntesis del derecho que debe enseñarse desde la representación institucional. Hay tres "etc." en el párrafo que excluyen del campo de lo dicho a aquello que es repelido por una concepción formal del derecho. El primer "etc." probablemente aluda a las disciplinas (consideradas marginales en nuestras carreras de derecho) que pueden aportar una mirada no formalista del derecho y el segundo tal vez haga referencia a los diversos modos de ejercicio de las profesiones jurídicas que van más allá de los ejercicios tradicionales. En cuanto al último, creo que es un reconocimiento de la inabarcabilidad de un objeto (el orden normativo) que, por más que se quiera atrapar, necesariamente se escapa. Es la evidencia del fracaso de esa pretensión enciclopedista que el formalismo eleva.

Vale recordar aquí algo que Llewellyn señalaba en un clásico artículo: "si lo único que puede hacer el abogado es informar cuál es, la regla correcta desde el punto de vista doctrinario, entonces pertenece

\footnotetext{
${ }^{12}$ LISTA, Carlos y BEGALA, Silvana, "Los resultados de una socialización exitosa: la reproducción del modelo jurídico dominante", 2009, p. 137.

${ }^{13}$ Facultad de Ciencias Jurídicas y Sociales, UNLP, Diagnóstico e ideas preliminares para la modificación del plan de estudios de la FCJyS de la UNLP, 2002, p. 18.
} 
a esa clase de disciplina acerca de la cual un triste alemán observaba en cierta ocasión que 'El día de mañana, la legislatura puede derogar toda mi Wissenschaft'". ${ }^{14}$ Efectivamente, si la carrera de derecho tiene como principal y hasta excluyente objetivo transmitir los contenidos normativos, pareciera que hace honor a aquella caricatura del profesor diciéndole al alumno: no me lo diga de memoria pero dígamelo con las palabras de la ley.

Por supuesto la formación jurídica encierra el conocimiento de normas. Eso no está en duda. Lo criticable es que el derecho se reduzca a su faz normativa. En este sentido, Pérez Lledó responde su propia pregunta, ¿Y qué tiene el formalismo para ser una cosa tan mala?: "me limitaré a decir sólo dos cosas: 1) Desde un punto de vista teórico, una visión formalista es una mala visión del Derecho. El formalismo está equivocado. El Derecho es mucho más indeterminado que lo que la visión formalista tradicional suponía, y su hermética cerrazón ante la dimensión social y la valorativa es simplemente un mito inalcanzable... (El) formalismo (está) hoy bastante desprestigiado: también en España, todo el mundo quiere sacarse de encima esa etiqueta; y sin embargo, yo creo que, por más que cuando uno entra en un discurso teórico acerca de las ideas formalistas presentadas en abstracto casi todos reniegan de ellas, luego, en el trabajo cotidiano, y especialmente en la docencia, muchos vuelven a las andadas, quizá casi sin darse cuenta. 2) Desde un punto de vista práctico, el formalismo representa una imagen falsa de 'necesariedad' del Derecho que resulta 'autoparalizante': degrada la actividad del jurista a la de mero autómata, incapacita al jurista práctico para un ejercicio profesional más activo, para emprender con autoconfianza la tarea de una elaboración argumentativa del derecho que desemboque en mejores éxitos prácticos. Y, peor aún, es política y moralmente paralizante. Representa una rendición de antemano ante las supuestamente nulas o muy limitadas posibilidades de actuación política transformadora y de avance moral que permitiría el trabajo práctico con el Derecho tomado éste en su literalidad prima facie o a lo sumo estabilizado mediante las interpretaciones dominantes en la comunidad jurídica. En este sentido, el formalismo es conservador. Por eso creo que es fundamental que una buena enseñanza del Derecho se propusiera, entre sus finalidades básicas, la de educar juristas no formalistas" 15 . Efectivamente, en el campo jurídico se suele huir del mote de "formalismo" pero sólo para zambullirse en él a la hora de aplicar el derecho y reproducirlo en la instancia de socialización de nuevos juristas.

\section{Clase magistral}

La clase magistral, por las razones apuntadas, es la estrategia de enseñanza que más se adapta al formalismo jurídico. Dice al respecto Böhmer: “( $\mathrm{Si}$ ) el derecho (es) una ciencia que tiene por objeto la descripción de las normas positivas, entonces saber derecho es equivalente a conocer las normas. Y ¿qué mejor forma de hacerlas conocer que exponiéndolas? ¿Qué otra manera de demostrar que se sabe derecho que repitiéndolas?"16.

En un trabajo de investigación que realizamos en la Facultad de Ciencias Jurídicas de la Universidad Nacional de La Plata e incluyó observación de clases y entrevistas a docentes, pudimos corroborar que la clase magistral es la estrategia didáctica que mayor presencia tiene. A la hora de justificarla, los docentes no hacen referencia al que acaso sería el argumento esperable: es la técnica más apropiada

\footnotetext{
${ }^{14}$ LLEWELLYN, Karl, "El derecho y las ciencias sociales, especialmente la sociología”, 2003, p. 99.

15 PÉREZ LLEDÓ, Juan Antonio, "Teoría y práctica en la enseñanza del Derecho" 2007, pp. 97-98.

${ }^{16}$ BÖHMER, Martín “Algunas sugerencias para escapar del silencio del aula”, 2003, p. 23
} 
para dar mayor cantidad de contenidos en menor tiempo. La fundamentan, en cambio, en el excesivo número de alumnos y la apatía de los mismos, que tornan imposible promover métodos más "participativos". Nos decía un profesor titular: "La masividad impide cualquier técnica didáctica salvo la clase magistral; hay un impedimento de base a la posibilidad de implementar herramientas didácticas, pedagógicas y educativas porque mientras se tengan 140 alumnos, no hay otro destino que la clase expositiva". ${ }^{17}$ Vale resaltar que en las observaciones de las clases y las consultas de actas pudimos determinar que los profesores exageraban el número de alumnos, es decir, tenían la percepción de que eran más de los que realmente eran y, por otra parte, está claro que la participación, si no se promueve, difícilmente se producirá así como que contamos con estrategias didácticas diferentes para trabajar con grandes grupos; por otra parte, los profesores cuentan con auxiliares que podrían prestar colaboración en la implementación de esas estrategias áulicas. Durante las clases observadas, en cambio, dichos auxiliares tuvieron la misma actitud pasiva que los alumnos, es decir que conformaron el auditorio de la clase magistral.

En el marco de la misma investigación que acabo de mencionar, decidimos realizar observaciones de un grupo de profesores seleccionados a partir de la indagación que hicimos a un grupo de alumnos que los señaló como promotores de "buenas prácticas" de enseñanza. En el curso de esas observaciones descubrimos que, si bien en general los docentes escogidos se mantenían dentro de los límites de la clase magistral (acaso en esa periferia que al interior de la propia institución suele llamarse "exposición dialogada"), los rasgos que los distinguían con respecto al resto de los docentes observados eran los siguientes:

Se mostraban preocupados por el proceso de aprendizaje y lo ponían en evidencia al interrumpir el relato para preguntar a los alumnos si tenían dudas, si seguían la argumentación. Al observar a los alumnos, se percibía que generaban confianza en ellos. La confianza, al decir de Cornú, es "una hipótesis sobre la conducta futura del otro. Es una actitud que concierne al futuro, en la medida en que este futuro depende de la acción de otro. Es una especie de opuesto que consiste en no inquietarse del no-control del otro y del tiempo". ${ }^{18}$ Este abandono de la noción de control absoluto de la palabra y del auditorio también se registra en las entrevistas que realizamos a esos docentes. Pudimos detectar pues cierto nivel de diálogo aunque hay que marcar que, si bien la palabra era distribuida por el docente, no abundaban los diálogos argumentativos. En general, los docentes interpelaban a los alumnos acerca de si poseían algún conocimiento previo considerado indispensable para la comprensión de los contenidos abordados, y los alumnos interrumpían el monólogo del docente para pedir alguna aclaración pero difícilmente para hacer alguna objeción o presentar una posición diferente.

Incorporaban casos, relatos, que rompían la pura teorización o examinaban la interpretación del derecho. Esos casos y relatos muchas veces provenían de algo que el docente traía del mundo exterior: una relación con otros operadores jurídicos, con clientes, con funcionarios pero nunca con personas que no pertenecieran al campo jurídico. Esos momentos de la clase adquirían el tono de secretos revelados del iniciado en el campo a aquellos que todavía no han ingresado a ese campo.

\footnotetext{
${ }^{17}$ Fragmento de testimonio recogido en el marco de las entrevistas a profesores realizadas en el curso del Proyecto "El proceso de enseñanza, aprendizaje y evaluación en la FCYyS de la UNLP”, dirigido por Manuela González y Nancy Cardinaux, 20052008, publicado en GONZALEZ, Manuela y CARDINAUX, Nancy, Los actores y las prácticas. Enseñar y aprender derecho en la UNLP, 2010.p. 164.

${ }^{18}$ CORNU, Laurence, "La confianza en las relaciones pedagógicas”, 2007, p. 19
} 
Entre docentes y alumnos siempre existía un código en común, una norma, una fuente del derecho a la que recurrían cual ritual litúrgico. Frecuentemente, los profesores pedían a algún alumno que leyera en voz alta un artículo o fragmento de una sentencia o de un texto de doctrina. Si bien la lectura era hecha por uno de los alumnos, luego en algunos casos la interpretación quedaba a cargo exclusivamente del docente mientras que en otro pocos, el texto se ponía a disposición del curso para la interpretación y aparecía tenuemente el contexto social de la norma, que va planeando desafíos a esa hermenéutica.

El espacio ocupado por el docente era central, como en toda clase magistral, pero -a diferencia de otros cursos- se veía muchas veces operar un equipo de trabajo. Esto implica que el profesor no delegaba en otros miembros de su cátedra las funciones que a él le corresponden, para que las lleven a cabo de la misma manera, sino que esos auxiliares docentes en formación ocupaban roles diversos, entre ellos los de organizar grupos de trabajo para actividades realizadas fuera del espacio de la clase. Esto desmiente por supuesto aquel presupuesto que aquí citamos de un docente que atribuía a la excesiva cantidad de alumnos la razón necesaria de la clase magistral.

En definitiva, en las clases observadas, los docentes, aún dentro de los márgenes de la clase magistral, asumen el protagonismo pero también la responsabilidad por el proceso de aprendizaje, se muestran preocupados por establecer un lazo con los alumnos, se interesan por ellos, tratan de darles la palabra. Es posible que hayan llegado pues al límite de la clase magistral. Otros docentes, que van más allá, suelen quejarse de que sus alumnos resisten lo que consideran invasivo, muy diferente a aquello que a que están habituados, que los saca del rol en el que han sido socializados. ${ }^{19}$

En síntesis, la pareja formalismo-clase magistral ha recibido las mayores críticas de parte de quienes investigan la pedagogía jurídica y también de profesores que, sin dedicarse a investigarla, reflexionan sobre sus propias prácticas. En los representaciones de los alumnos y egresados recientes, en cambio, si bien aparecen algunas críticas a este binomio, el principal cuestionamiento a la educación legal es otro y a él nos dedicaremos a continuación.

\section{Demandas de los alumnos vs. demandas sociales}

En los diversos trabajos de indagación de alumnos con que contamos en el país, la mayor demanda que dirigen a sus facultades es que les brinde una capacitación más ajustada a los requerimientos que asignan al mundo laboral. Digo que asignan porque, en general, cuando son interrogados, no tienen claro cuáles son esos requerimientos. Y las pocas investigaciones con que contamos en ese ámbito, reflejan una gran dispersión de esos requerimientos.

La demanda de los alumnos, muchas veces transformada en lema por las agrupaciones estudiantiles es: 'más práctica y menos teoría'. Se trata de una demanda que nos vemos precisados a interrogar. En primer lugar, hay que aclarar que en nuestro país las facultades de derecho no habilitan para el ejercicio profesional; esta habilitación corre por cuenta de los colegios de abogados aunque se reduce a un mero trámite que no requiere instancia de capacitación alguna. ${ }^{20}$ Por otra parte, un número importante de alumnos se inserta laboralmente en la administración de justicia y allí la capacitación suele hacerse en

\footnotetext{
${ }^{19}$ GONZALEZ, Manuela y CARDINAUX, Nancy, “Los actores y las prácticas. Enseñar y aprender derecho en la UNLP”, p. 249.

${ }^{20}$ En general, esos colegios ofrecen a sus matriculados (es preciso aclarar además que rige un sistema de matriculación obligatoria para la práctica de la abogacía) cursos de formación profesional pero no son obligatorios.
} 
la práctica aunque para ocupar cargos de funcionario o magistrado, las escuelas judiciales otorgan un puntaje específico. En cuanto al nivel de posgrado, de ninguna manera es posible sostener que están dirigidos a otorgar a los alumnos esos conocimientos "prácticos" que reclaman. Aún en el nivel de los cursos de actualización y las carreras de especialización, en general no están orientados a desarrollar esas competencias.

Una pregunta razonable es si las facultades de derecho pueden enseñar esa práctica reclamada. Kennedy sostiene, por un lado, que las facultades de derecho podrían hacerlo si modificaran sus programas y, por otro lado, afirma que los estudiantes que no tienen habilidades prácticas exageran las dificultades de adquirirlas. Y estas dos circunstancias dejan a los alumnos la única opción de incorporarse a una gran empresa de abogados que brinde el training necesario al costo de una relación laboral claramente desventajosa. ${ }^{21} \mathrm{Si}$ bien acuerdo con esto último, ya que en nuestro país las empresas de abogados toman en calidad de pasantes a muchos de nuestros estudiantes, así va generándose una relación laboral en general muy despareja para los jóvenes abogados bajo la excusa de que están completando su formación, se entiende que así como hay que interrogar qué se comprende por "teoría", también debemos preguntarnos a qué llamamos capacitación práctica. Si se trata de la socialización profesional rutinaria, es algo que la universidad no puede ni debe transmitir. ${ }^{22}$ Esa capacitación es un know how que se aprende en el ejercicio y, en todo caso, lo que habría que reformular es el sistema de pasantías o primeros empleos (muchas veces informales y con muy bajos sueldos y, hasta hace poco tiempo, como meritorios en la administración de justicia), a través del cual los egresados de derecho adquieren sus destrezas profesionales. Por otra parte, aunque se mejoren las condiciones de contratación, esas prácticas muchas veces tienen un problema en sí, y es que son reproductoras de las formas de ejercicio consolidadas que muchas veces a las facultades de derecho les interesa combatir o, al menos, abrir el abanico de otras formas posibles de ejercicio de las profesiones jurídicas.

Dice Goldfarb sobre los cursos de práctica profesional: "El peligro reside en que la educación práctica se circunscriba a transmitir aptitudes prácticas y deje de lado el contenido normativo y las consecuencias inherentes a la actividad de los abogados. Otro de los peligros consiste en que los docentes de los prácticos, al estar tan concentrados en la particularidad de la amplia variedad de casos analizados, dejen de lado el contexto cultural que influye y explica los patrones resultantes. En algunas ocasiones, la educación práctica ha advertido que estos peligros refuerzan la idea caricaturizada que algunos tienen de los cursos de práctica profesional en cuanto a que, contrario a la imagen que se presenta en este trabajo, éstos constituyen una actividad antiintelectual" 23 .

La perspectiva de género acaso nos ayude a poner en crisis el binomio teoría-práctica, y pensar que seguramente son igual de dificultosos los procesos de enseñanza y aprendizaje de teoría y de práctica. El clivaje teoría-práctica quizás no sea parte más que de un estereotipo y poco tenga que ver con los

\footnotetext{
${ }^{21}$ KENNEDY, Duncan, "La educación legal como preparación para la jerarquía”, 2003, p. 135.

${ }^{22}$ En este mismo sentido, dice Bull, refiriéndose a los estudios de derecho en Alemania: "Uno de los clichés más comunes es que la formación jurídica padece un exceso de teoría o un alejamiento de la práctica. Pero más bien diría que adolece mucho más de una desvalorización de la teoría y de una exageración de supuestos elementos prácticos, que padece un sobrepeso de rutinas y reglas del oficio y que en lugar de fomentar una metodología adecuada, genera una aplicación esquemática e irreflexiva del derecho”. BULLER, Hans Peter, “¿De una facultad de derecho hacia una Fachhochschule con nociones básicas de derecho?", 2005, p. 122.

${ }^{23}$ GOLDFARB, Phyllis, "Una espiral entre la teoría y la práctica. La ética del feminismo y la educación práctica”, 2005, p. 135.
} 
hechos. En efecto, en el campo de la investigación científica, es muy difícil diferenciar teoría de práctica; la "teoría pura" tiene consecuencias muy prácticas y todos los sabemos muy bien porque justamente en el canon de nuestra formación jurídica está un libro que lleva ese concepto en su título. Nada más práctico que una buena teoría, como sostenía Kant, y acaso nada más necesitado de teorización que una buena práctica.

Es importante en este punto desmarcar esta imbricación de teoría y práctica de la noción de competencia, que tanta influencia ha tenido durante las últimas décadas sobre los proyectos de reforma de las carreras de derecho y, actualmente, sobre la formación de jueces. El proyecto Tuning-América Latina, que implicó a un conjunto de universidades e incluyó las carreras de derecho, marcó el límite que ese enfoque tiene en este campo: "Una de las dificultades que el grupo de trabajo encontró en esta disciplina se debió a la larga historia que la carrera posee en lo que respecta a la organización curricular, metodología de enseñanza, objetivos de aprendizaje, todo lo cual ha resultado en principio extraño al modelo de formación por competencias. En efecto, el grupo de trabajo entendió que la dogmática jurídica era la "matriz teórica dominante" en la mayor parte de las facultades, con énfasis metodológico en la transmisión de contenidos teóricos por parte del docente y la absorción de éstos por los estudiantes". ${ }^{24} \mathrm{El}$ grupo hace notar, además, que la multiplicidad de actividades profesionales que ejercen los egresados de derecho es también un obstáculo para aplicar la formación por competencias. Este último punto del diagnóstico deja abierta la puerta para la aplicación de dicha formación en la socialización profesional, ya sea en las escuelas judiciales para los magistrados o en las pasantías para los abogados litigantes. En cuanto a los demás obstáculos señalados, se puede discutir si dan lugar a la deserción del enfoque pero me parece importante señalar que aquello que se considera es el núcleo duro de la educación formalista, es desde esta perspectiva prácticamente imposible de deshacer a través de la formación por competencias ${ }^{25}$.

De esta noción de competencias, que es muy difícil precisar, acaso el único vértice que me interesa capitalizar sea aquel que parte de la teoría de la actividad situada: "Desde esta posición se entiende que el conocimiento, en una cantidad importante de profesiones, transcurre dentro de los sistemas de actividad que se desenvuelven social, cultural e históricamente. Las teorías de la actividad situada no establecen una separación entre acción, pensamiento, sentimiento y valor y sus formas colectivas e histórico-culturales de actividad localizada, interesada, conflictiva y significativa"26. Esta interseccionalidad es importante porque nos hace pensar que, en lugar de ver la teoría y la práctica como contrincantes que compiten en un juego de suma cero, pueden ser perfectamente enseñadas a la vez. Hay algo, sin embargo, que parece que los alumnos y egresados recientes tienen muy claro: la práctica que reclaman no puede ser enseñada a través de la estrategia de la clase magistral y excede los límites de una concepción formalista del derecho formalista. Es aquí donde pueden verse especularmente las críticas al binomio formalismo-clase magistral y estas otras críticas a la falta de práctica $^{27}$.

\footnotetext{
${ }^{24}$ RUIZ, Guillermo, "La educación por competencias: definiciones y alcances de su aplicación en la formación judicial”, mimeo en prensa.

${ }^{25}$ BENEITON, Pablo et. al. , Reflexiones y perspectivas de la educación superior en América latina. Informe final Proyecto Tuning América Latina 2004-2007, 2007, p. 109.

${ }^{26}$ CAPPELLETTI, Graciela, “La evaluación por competencias”, 2010, p. 178.

${ }^{27}$ Más allá de estas nociones y de los múltiples enfoques desde los que puede pensarse las competencias (constructivista, funcionalista, conductista, etc.), la formación por competencias es un modelo que no revista consecuencias positivas en la formación jurídica. Al respecto dicen Bullard y Mac Lean: “¿Cuáles son las razones existentes detrás de esta corriente de la
} 
Aquí es donde es dable preguntarse si las facultades de derecho pueden operar contraculturalmente, es decir enseñar aquello que no se está demandando o, mejor dicho, que los actores que son interpelados no demandan. Esos actores son los que configuran el campo jurídico. Más allá, hay una sociedad profundamente desigual y diversa que posiblemente esté demandando abogados, jueces, funcionarios capaces de trabajar contra esa desigualdad y a favor de esa diversidad. La pregunta, sobre todo en las universidades públicas es hasta qué punto no es preciso cambiar las reglas del campo laboral y, por extensión, del campo jurídico mismo. Estamos llevando a cabo, por ejemplo, una investigación sobre litigación compleja en la que estamos tratando de determinar el grado de incidencia que la formación jurídica ha tenido sobre la permeabilidad de los jueces a los casos complejos y también sobre los ejercicios profesionales no tradicionales.

En general, en las instancias de cambios curriculares, que suele ser cuando las carreras jurídicas son objeto de reflexión en las universidades públicas, los actores involucrados en el proceso de cambio son los que se encuentran dentro del campo jurídico. Ese parece ser un gran error porque hay que incorporar al diálogo a otros actores, a la sociedad ampliada, que dirige sus demandas de reconocimiento y provisión de derechos y, para hacerlas efectivas, tal vez requiera de nuevos tipos de profesionales del derecho.

A continuación presentaré una posible tipificación que, en sus extremos, une las concepciones del derecho con las estrategias de enseñanza. Se comprende que, además de su potencial heurístico, puede ayudarnos a determinar en qué sentido se puede reconfigurar el rol docente, lo cual sabemos que es muy difícil por cuanto la biografía como estudiantes que portamos los docentes todo el tiempo tensiona hacia la reproducción de lo que nuestros maestros han hecho.

\section{Concepciones del derecho y estrategias de enseñanza}

A la pregunta ¿qué es el derecho? se le pueden dar diversas respuestas por cuanto existen distintas concepciones acerca del derecho, que luego nos ocuparemos de tipificar. En cualquiera de esas concepciones, la aplicación del derecho requiere ciertas operaciones de interpretación. Y dichas operaciones están determinadas por métodos interpretativos, que son "procedimientos mediante los cuales se lograría obtener un conocimiento adecuado del derecho objetivo que, por alguna razón, no conseguiría transmitir claramente su mensaje normativo al sujeto receptor" 28 .

La interpretación que toda aplicación del derecho demanda puede ser vista como un acto creador que

formación por competencias? Básicamente se trata de una razón económica y de desarrollo personal. Lo que sucede es lo siguiente: la globalización y la revolución tecnológica... han ocasionado el cambio en la estructuración de las empresas que ahora es más plana ya que ha cambiado la noción de puesto de trabajo por la de área de ocupación. El individuo ahora debe preocuparse por mantenerse empleable, es decir que tenga la posibilidad de ubicarse y permanecer empleado hasta que decida moverse a otro empleo que le permitirá desarrollar nuevas competencias. En otras palabras, debemos cambiar una visión estática de la formación (un stock de conocimientos) por una visión dinámica (un flujo de competencias). BULLARD, Alfredo y MAC LEAN, Ana, “La enseñanza del derecho: ¿cofradía o archicofradía?”, 2009, p. 39

${ }^{28} \mathrm{El}$ mismo autor aclara que los métodos tienen además otra función: son "prescripciones dirigidas a los órganos que cumplen funciones de aplicación y producción del derecho". En este sentido, los métodos interpretativos son regulativos, es decir que son normas de derivación en tanto sirven para obtener normas a partir de normas. VERNENGO, Roberto, Curso de teoría general del derecho, Cooperadora de Derecho y Ciencias Sociales, Buenos Aires, 1976. 
está limitado pero no inhibido por el derecho mismo. Esto implica que no se puede hacer decir cualquier cosa al derecho. La aseveración según la cual "la mitad de la biblioteca sustenta la interpretación A y la otra mitad apoya la interpretación B" sólo puede tener asidero en determinadas situaciones dilemáticas; en el resto de los casos, es posible encontrar mejores argumentos para sostener una interpretación que otra. ${ }^{29}$ Ello sin olvidar que en derecho hay casos a los que podemos considerar "fáciles" mientras que otros son "difíciles", tienen zonas de penumbras y en ocasión dan lugar a aporías. Esto hace que la labor interpretativa suponga una gran carga argumentativa solamente en algunos casos. Del mismo modo, hay ocasiones en que anteriores interpretaciones de una norma pueden ser aplicadas porque el caso nuevo que lo requiere tiene gran parecido con el anterior; mientras que en otras ocasiones aparecen casos nuevos o bien se producen cambios sociales que ameritan arrojar nueva luz sobre conceptos indeterminados comprendidos en las normas jurídicas.

Aclarado entonces que la concepción del derecho y su método de interpretación van de la mano, podemos formular nuestra hipótesis de trabajo: la concepción del derecho de la que partimos y el método de interpretación del derecho que surge de dicha concepción condicionan el método de enseñanza del derecho y este último se encarna en una estrategia didáctica prevalente. Esto no supone que quienes enseñan derecho hayan reflexionado acerca de qué es el derecho y qué método de interpretación es coherente con esa respuesta. Sería deseable que así fuera, pero entendemos que el método de enseñanza del derecho y sus estrategias llevan implícitas una concepción del derecho y un método de interpretación, más allá de que estos dos últimos sean explícitos o no para el agente educador

La metodología que implementaremos será la construcción de tipos ideales. Las concepciones del derecho serán tipificadas que va siguiendo una tradicional presentación, aunque es preciso aclarar que trataremos a cada una de ellas como tipos ideales weberianos, es decir como abstracciones unívocas que pretenden atrapar un sentido determinado del derecho. Algunas de estas concepciones responden a tipos históricos mientras que otras tienen un perfil más teórico, ya que no han logrado preeminencia dentro de la cultura jurídica. ${ }^{30}$ En tanto tipos ideales, sólo son útiles como instrumentos que nos sirven para aproximarnos a la realidad y determinar en qué medida predominan los caracteres de un tipo determinado y luego observar los caracteres residuales que pertenecen a otros tipos diseñados.

Descriptas ya brevemente nuestra metodología, nos dedicaremos ahora a elaborar los tipos con el objetivo de caracterizar en mayor detalle la conjetura de la que partimos, que estipula que cada concepción del derecho define un objeto de interpretación y estos elementos encuentran correlación

\footnotetext{
${ }^{29}$ Dice Alexy: "El Tribunal Constitucional de Alemania expresó, en una decisión del año 1990, el concepto conforme al cual „la interpretación, en particular del derecho constitucional, ... (tiene) el carácter de un discurso, en el que se hacen valer argumentos a los que se contraponen otros argumentos, debiendo darse finalmente predominio a los mejores argumentos ${ }^{\text {ee" }}$ Ver: ALEXY, Robert, Teoría del discurso y derechos humanos, 1995, p. 35.

${ }^{30}$ Habermas define a la cultura jurídica como "las ideas, opiniones, valores y actitudes acerca del derecho, que la gente trae consigo en sus cabezas" (HABERMAS, Jürgen, Facticidad y validez. Sobre el derecho y el Estado democrático de derecho en términos de teoría del discurso, 2001. p. 476). Este concepto se diferencia del de paradigma jurídico, que es "algo que en primera línea se infiere de las decisiones judiciales que, en virtud de los criterios que fuere, se consideran ejemplares, y la más de las veces suele equipararse a la imagen implícita que la sociedad tiene de los jueces". (HABERMAS, Ibíd. p. 473) Ambos conceptos están implicados por cuanto estos paradigmas impactan sobre la cultura jurídica y a la vez la cultura jurídica puede demandar ciertos cambios de paradigma.
} 
en un método de enseñanza del derecho y una estrategia didáctica prevalente.

\begin{tabular}{|c|c|c|c|c|}
\hline & $\begin{array}{l}\text { ¿Qué es el } \\
\text { derecho? }\end{array}$ & $\begin{array}{ll}\text { ¿Cómo } & \text { se } \\
\text { interpreta? } & \end{array}$ & $\begin{array}{l}\text { ¿Qué se debe } \\
\text { enseñar? }\end{array}$ & $\begin{array}{l}\text { ¿Cuál es la } \\
\text { estrategia } \\
\text { didáctica } \\
\text { más } \\
\text { idónea? }\end{array}$ \\
\hline EXÉGESIS & La ley & $\begin{array}{l}\text { Determinando } \\
\text { la voluntad del } \\
\text { legislador } \\
\text { (pueblo) }\end{array}$ & $\begin{array}{l}\text { La letra de la } \\
\text { ley }\end{array}$ & $\begin{array}{l}\text { Clase } \\
\text { magistral }\end{array}$ \\
\hline HISTORICISMO & $\begin{array}{l}\text { Un hecho de } \\
\text { formación } \\
\text { espontánea }\end{array}$ & $\begin{array}{l}\text { Desentrañando } \\
\text { el espíritu del } \\
\text { pueblo }\end{array}$ & $\begin{array}{l}\text { Hermenéutica } \\
\text { antropológica }\end{array}$ & $\begin{array}{l}\text { Recreación } \\
\text { del proceso } \\
\text { de } \\
\text { investigaci } \\
\text { ón } \\
\text { cualitativo }\end{array}$ \\
\hline UTILITARISMO & $\begin{array}{l}\text { Un mandato } \\
\text { social }\end{array}$ & $\begin{array}{l}\text { Estableciendo } \\
\text { la finalidad de } \\
\text { las normas }\end{array}$ & $\begin{array}{l}\text { Cálculo de } \\
\text { beneficios } \\
\text { (utilidad vs. } \\
\text { pérdidas) en } \\
\text { orden al bien } \\
\text { común }\end{array}$ & $\begin{array}{l}\text { Recreación } \\
\text { del proceso } \\
\text { de } \\
\text { investigaci } \\
\text { ón } \\
\text { cuantitativ } \\
\text { o }\end{array}$ \\
\hline REALISMO & $\begin{array}{l}\text { Hecho, } \\
\text { conducta, } \\
\text { experiencia }\end{array}$ & $\begin{array}{l}\text { Generando } \\
\text { reglas y } \\
\text { prediciendo sus } \\
\text { posibles } \\
\text { efectos }\end{array}$ & $\begin{array}{l}\text { Previsión } \\
\text { racional a } \\
\text { través de las } \\
\text { ciencias } \\
\text { sociales }\end{array}$ & $\begin{array}{l}\text { Método } \\
\text { socrático } \\
\text { en base a } \\
\text { casos } \\
\text { judiciales }\end{array}$ \\
\hline SISTEMÁTICA & $\begin{array}{l}\text { Sistema } \\
\text { normativo }\end{array}$ & $\begin{array}{l}\text { Contextualizan } \\
\text { do la norma en } \\
\text { el sistema } \\
\text { normativo }\end{array}$ & $\begin{array}{l}\text { Análisis } \\
\text { lógico del } \\
\text { plexo } \\
\text { normativo y } \\
\text { de las } \\
\text { construccione } \\
\text { s dogmáticas } \\
\text { que le dan } \\
\text { sentido }\end{array}$ & $\begin{array}{l}\text { Clase } \\
\text { magistral }\end{array}$ \\
\hline $\begin{array}{l}\text { ANÁLISIS } \\
\text { CRÍTICO }\end{array}$ & $\begin{array}{l}\text { Conjunto de } \\
\text { prácticas } \\
\text { reproductora } \\
\mathrm{s} \text { del statu } \\
\text { quo }\end{array}$ & $\begin{array}{l}\text { Denuncia de } \\
\text { las estrategias } \\
\text { de dominación } \\
\text { y/o explotación } \\
\text { estratégica de } \\
\text { los recursos } \\
\text { disponibles a }\end{array}$ & $\begin{array}{l}\text { Reconocimien } \\
\text { to de la base } \\
\text { ideológica del } \\
\text { derecho y/o } \\
\text { fortalecimient } \\
\text { o de las } \\
\text { destrezas que }\end{array}$ & $\begin{array}{l}\text { Recreación } \\
\text { del proceso } \\
\text { de } \\
\text { investigaci } \\
\text { ón } \\
\text { histórico y } \\
\text { social. }\end{array}$ \\
\hline
\end{tabular}




\begin{tabular}{|c|c|c|c|c|}
\hline & & $\begin{array}{l}\text { favor de los } \\
\text { desaventajados }\end{array}$ & $\begin{array}{l}\text { habiliten un } \\
\text { incremento } \\
\text { del acceso a la } \\
\text { justicia }\end{array}$ & \\
\hline $\begin{array}{l}\text { DELIBERATIVIS } \\
\text { MO }\end{array}$ & $\begin{array}{l}\text { Conjunto de } \\
\text { prácticas } \\
\text { sociales } \\
\text { moralmente } \\
\text { legitimadas } \\
\text { a través de } \\
\text { un proceso } \\
\text { de } \\
\text { deliberación } \\
\text { pública que } \\
\text { respete } \\
\text { ciertos } \\
\text { derechos } \\
\text { fundamental } \\
\text { es }\end{array}$ & $\begin{array}{ll}\text { Elabora la } & \text { la } \\
\text { mejor vía en } \\
\text { orden a la } \\
\text { protección de } \\
\text { los } \\
\text { procedimientos } \\
\text { de deliberación } \\
\text { pública en la } \\
\text { creación del } \\
\text { derecho }\end{array}$ & $\begin{array}{l}\text { Entrenamient } \\
\text { o en la } \\
\text { deliberación, } \\
\text { balanceando } \\
\text { la moral ideal } \\
\text { con los límites } \\
\text { que la } \\
\text { democracia } \\
\text { real fija }\end{array}$ & $\begin{array}{l}\text { Método de } \\
\text { casos } \\
\text { reales e } \\
\text { hipotéticos } \\
\text { reformulad } \\
\text { o y juego } \\
\text { de roles }\end{array}$ \\
\hline
\end{tabular}

\section{Exégesis}

El derecho moderno, legitimado por un proceso de creación cuyo sujeto es el pueblo, suele identificarse con la ley escrita. En esta concepción, el derecho es la ley y esa ley tiene como principal función legitimar y limitar el poder estatal de modo tal que los individuos ejerzan el máximo de libertad posible. La ley proviene así del pueblo y es una barrera que protege a los ciudadanos de un poder cuya fortaleza varía según la doctrina teórica que lo fundamente.

Si el derecho es producto del pueblo se supone que ese mismo pueblo puede entenderlo y aplicarlo. Por eso, se mira con gran desconfianza a aquellos que pueden distorsionar la voluntad del pueblo expresada en la ley, que no son otros que los encargados de interpretarla cuando surge un conflicto: los jueces. Esta desconfianza era razonable en aquellos casos en los que se habían producido cambios revolucionarios, ya que los jueces solían ser representantes del antiguo régimen y por lo tanto no bastaba con cambiar las normas sino que además era preciso encorsetar a sus intérpretes para que no hicieran decir a las leyes algo diferente a lo que el pueblo o sus representantes tuvieron intención de decir.

Al sentar las bases del derecho penal moderno, Beccaria establece, entre otros, dos importantes principios: sólo las leyes pueden decretar las penas contra los delitos y no la voluntad del juez, y la interpretación de la ley corresponde al legislador y nunca al juez. Decía Beccaria:

Si es un mal la interpretación de la leyes, es otro evidente la oscuridad que arrastra consigo necesariamente la interpretación, y aún lo será mayor cuando las leyes estén escritas en una lengua extraña para el pueblo, que lo ponga en la dependencia de algunos pocos, no va pudiendo juzgar por sí mismo cuál será el éxito de su libertad o de sus miembros en una lengua que forma de un 
libro público y solemne uno casi privado y doméstico ${ }^{31}$.

Se estipula de esta manera que el derecho debe ser tan claramente establecido que no queden dudas con respecto al significado de sus palabras. Se dice que, ante la primera aparición de un comentario a su Código Civil, Napoleón expresó: "mi Código está muerto"; esta anécdota marca el apego a una ley que se presume clara y por tanto prescinde de intermediarios que no harían más que aplicar extraños métodos que desvirtuarían los propósitos para los cuales fue creada ${ }^{32}$.

Esta posición radical puede ser matizada si caemos en la cuenta de que alguna labor de interpretación debe llevarse a cabo toda vez que un mandato abstracto se aplique a una acción o situación específica. Y si se acepta alguna mediación heurística, se lo hace bajo el supuesto de que la ley es la manifestación de la voluntad del legislador y por ende la interpretación se propone como tarea recrear esa voluntad. Se denomina "exégesis" a la indagación acerca de qué quiso decir efectivamente el autor, lo cual supone establecer la supuesta voluntad histórica del legislador real.

Pero aún al acordar que el derecho es equivalente a la ley escrita y ésta refleja fielmente la voluntad del legislador, queda por averiguar quién es el legislador. Tratándose de sistemas republicanos, el legislador es el pueblo, pero ese pueblo actúa en las repúblicas modernas a través de representantes y la ley -sobre todo ciertas leyes como las constituciones o los códigos- no suelen cambiar a menudo, por lo que se torna dificultoso determinar si el legislador es aquel pueblo que, a través de sus representantes, sancionó una ley o si es el pueblo actualizado que hoy sigue sustentando esas leyes. También el legislador suele ser confundido con el redactor que escribió las leyes y esto ha hecho que no pocas veces se indague cuidadosamente la intención de ese técnico a la hora de determinar el sentido de sus palabras. Así, por ejemplo, en la doctrina jurídica se ha discutido el peso que debe atribuirse a las notas de Vélez Sarsfield al Código Civil o la importancia que el pensamiento alberdiano tiene para interpretar la Constitución Nacional.

La exégesis en su versión más conservadora se dirige al pasado, que trata de esclarecer el sentido originario de las normas, que el tiempo habría oscurecido y confundido. Al no poder consultar directamente al autor, la voluntad debe ser inferida de los documentos en los que fue expresada esa voluntad y para ello se llevan a cabo cuidadas investigaciones de los antecedentes históricos de una norma que incluyen la legislación comparada que el legislador tomó en cuenta o reprodujo, sus notas, etc.

Esta concepción exegética del derecho, que hace de la ley el objeto de interpretación y trata de valerse de una heurística literal que reproduce la voluntad del legislador encuentra su método adecuado de enseñanza en la transmisión de la letra de la ley. En su campaña para acceder a la presidencia argentina en 1983, el candidato Alfonsín solía terminar sus discursos con el recitado del Prólogo de la

\footnotetext{
${ }^{31}$ BECCARIA, Cesare, De los delitos y las penas, 1994, p. 33.

${ }^{32}$ Como es bien sabido, antes de la sanción del Código Civil francés, en 1804, se produjo una fuerte discusión doctrinaria en cuanto a la conveniencia o no de codificar el derecho. La codificación supuso un cambio importante en la preeminencia de las fuentes del derecho, ya que más allá de que la costumbre, los principios generales del derecho o la jurisprudencia reservaran un peso importante, la ley escrita se transformó en la fuente principal del derecho. Desde luego, en el tipo que estamos describiendo no es la fuente principal sino que se presume que es la única.
} 
Constitución Nacional; ese "rezo laico" -como lo llama Landi ${ }^{33}$ - da perfecta cuenta del carácter pseudomágico atribuido a la palabra de la ley, como si esa ley arrastrara su eficacia con su sola enunciación.

Seguramente esa creencia podía sostenerse luego de un largo proceso militar que había arrasado con todos los derechos preestablecidos y con cualquier forma de creación popular de las leyes. Hoy sabemos que la ley encierra una serie de conceptos que deben ser operativizados para tornarse eficaces. Por eso, la exégesis no parece ser suficiente para que el derecho se torne acto. Sin embargo, esta repetición ritual de la letra de la ley está todavía muy extendida en la enseñanza del derecho, desde el nivel universitario hasta el inicial, donde muchas veces se recitan derechos cuyas palabras son incomprensibles para los niños que las invocan. En la película Danton de Vajda, el recitado de un niño de los derechos contenidos en la Declaración Universal era vigilado por la vara presta a golpearlo cada vez que cometía un error. Ese error es inadmisible cuando se entiende que la letra de la ley cumple una función mágica, ritual, y ahí anida acaso la razón por la que perduran tantos formalismos en el derecho, que solamente se entienden si nos remitimos a sus orígenes mágicos en los cuales el cambio de una palabra podía hacer que no se lograra el objetivo pretendido.

De todos modos, no podemos dejar de rescatar de la exégesis la pretensión de que el derecho sea por todos conocido. Desde distintas posiciones se ha instado a despojar el derecho de algunos formalismos que lo alejan a la par de producir una socialización que nos iguale en el ejercicio de nuestros derechos. De lo contrario, el ejercicio del derecho siempre requerirá de técnicos cuyos servicios no suelen estar a disposición de todos en condiciones de igualdad.

La clase magistral, por las razones apuntadas, se muestra como la estrategia didáctica más eficaz para reproducir ese derecho reducido a la letra de la ley. En muchos casos, el maestro, al elegir del interior de un enorme corpus normativo qué derecho enuncia, está marcando el derecho que se debe conocer y relegando al olvido el resto. En la escena, la luz está puesta sobre ese profesor que recita la ley. Un auditorio silencioso escucha ese monólogo que supuestamente no presenta lagunas, fisuras ni tergiversaciones.

\section{Historicismo}

A principios del Siglo XIX, Francia había codificado su derecho civil mientras que la vertiente historicista, de raigambre alemana, se oponía fuertemente al proceso de codificación, que va advirtiendo que el derecho es un hecho de formación espontánea. Savigny, uno de los mayores exponentes de esta línea doctrinaria, consideraba que el derecho es un hecho de formación espontánea y natural que vive en la conciencia popular y reviste el carácter peculiar del pueblo al que pertenece, de la misma manera que el lenguaje y las costumbres.

Decía Alfredo Colmo:

Savigny (...) ha enseñado, con doctrinas y con el ejemplo práctico de su libro, que la relación jurídica es un concepto de principios que arraigan en instituciones diversas; que, por consiguiente,

${ }^{33}$ LANDI, Oscar, Reconstrucciones. Las nuevas formas de la cultura política, 1988, p. 161. 
se equivoca quien pretenda explicarla aisladamente; que, por lo mismo, la norma de la ley es un concepto abstracto o vacío de sentido, cuya inteligencia se determina por la plural y recíproca vinculación que guarda con las demás que la integran; y, por último, las mismas instituciones no viven independientes, puesto que, como expresión de la 'conciencia jurídica' de un pueblo, son meros detalles del entero que constituye el Derecho correspondiente, cuya naturaleza y carácter imperan sobre todas ellas y les dan congruencia y fisonomía.... Ihering, que es quien más ha insistido en el contenido orgánico del derecho, en el carácter natural y espontáneo de la formación del mismo, en la determinación del espíritu que informa a las respectivas instituciones y preceptos, en la jurídica irrealidad de estos últimos que no son sino el 'alfabeto' del Derecho y que, como otras letras del alfabeto lingüístico, no tienen otra función que la de servir elementos para la institución (que viene a corresponder a la palabra y a la frase de este último), y que es así lo único que tiene sentido ${ }^{34}$.

El origen del derecho no debe buscarse según esta doctrina en el arbitrio del legislador, sino en una fuerza interior que actúa tácitamente. Siendo pues algo vivo e implícito, no puede quedar encerrado en un código porque correría el riesgo de ser cristalizado. Se considera que, como la lengua, el derecho es entonces el resultado de fuerzas y circunstancias históricas, entre las cuales se tiene especialmente en cuenta la tradición nacional del pueblo que lo genera.

Esta concepción del derecho considera que la interpretación correcta de una norma es la que coincide con el sentido que se le hubiese dado en el momento histórico de su promulgación, sentido que debía desentrañarse a través de la investigación de la tradición cultural de la nación. De este modo, el derecho entronca con la costumbre y evidentemente no tiene el carácter renovador que adquirió allí donde se consideraba que podía constituir una ruptura de las tradiciones. Mientras que la exégesis concluyó en una técnica de investigación documental, suele criticarse al método histórico que haya degenerado en un recurso que permitió incorporar criterios políticos basándose en la supuesta comprensión empática o contacto intuitivo con la conciencia jurídica de una nación, los propósitos de una institución o el "espíritu de la ley".

La interpretación jurídica historicista busca desentrañar "el espíritu del pueblo", con toda la indeterminación que este concepto trae aparejada. La enseñanza del derecho ya no se limita a la transmisión de la norma sino que requiere de una hermenéutica antropológica que aprecie, en las costumbres y tradiciones, las fuentes de la ley. Es por supuesto ésta una operación mucho más compleja que la de transmitir la letra de la ley, porque aquí la fuente principal del derecho es la costumbre y esas costumbres deben ser reconstruidas, hasta llegar a una suerte de esqueleto del derecho, del cual surgirán las normas aplicables a una situación o caso determinado.

Refiriéndose a las tradiciones en la enseñanza del derecho, decía Mefistófeles al estudiante: “¡Desgraciado de tí que eres nieto!”, en donde supone que todo lo que se le enseñaría era parte de unas tradiciones que le antecedían y continúa más adelante en lamentar la falta de enseñanza de derecho natural: "Del derecho que con nosotros ha nacido, de él, ¡ay! nunca se trata" 35 . Todo el derecho debe pues buscarse en esas tradiciones originales que a la postre pueden entroncar con antiguos derechos como el romano en el caso del derecho civil.

\footnotetext{
${ }^{34}$ COLMO, Alfredo, "Sobre didáctica del Derecho Civil. Principios y espíritu del nuevo Programa de Derecho Civil", 2011, p. 117.

${ }^{35}$ GOETHE, Johann Wolfgang, Fausto, 2006, p. 57.
} 
Entendemos que la estrategia de enseñanza del derecho en este caso queda emparentada a un proceso de investigación cualitativo que, por un lado, da cuenta del carácter fáctico de aquello que se trata de desentrañar y, por el otro, pretende dar cuenta de un contenido simbólico que ubica a la hermenéutica en el centro de la escena. Profesores y alumnos llevan adelante trabajos monográficos de interpretación que procuran desentrañar el sentido de la norma a través de un sondeo histórico y antropológico. Si bien no hemos incorporado los modelos de universidades en nuestro análisis, está claro que imaginamos un modelo de profesor investigador, capaz de conducir y acompañar ese proceso investigativo en el que los alumnos deben entrenarse.

\section{Utilitarismo}

Este tipo tiene su origen histórico en Inglaterra y en la original versión que debemos a Bentham, el derecho aparece claramente diferenciado del delineado por el historicismo, por cuanto este autor considera que es un conjunto de mandatos creados por el legislador en tanto órgano estatal. Pero junto a esta concepción del derecho, Bentham construye una teoría de la justicia que no está fundamentada en principios sino que está sustentada por un propósito: la utilidad social. Un acto o una decisión es justa en la medida en que produzca la mayor felicidad al mayor número de individuos. Son conocidos los trabajos de Bentham sobre la utilidad o no de la descentralización del poder, de la emancipación de las colonias (tanto para los habitantes de la metrópoli como de las colonias), de la organización de un nuevo sistema penitenciario, de la eficacia de las multas, etc.

Si la ley es un mandato que tiene como fin la utilidad social, el método de interpretación es la indagación del contenido de ese fin, que bien puede variar de época en época o de colectivo en colectivo. El utilitarismo ha dado lugar a numerosas vertientes que han tenido mayor desarrollo en el campo de la ética que en el del derecho aunque han impactado sobre este último especialmente a través de la elaboración de teorías de la justicia.

Si bien en derecho es difícil operar de modo utilitarista porque hay principios que se supone que deben cumplirse sin importar las consecuencias, desde la aparición de los dualismos éticos y de la ética de la responsabilidad, es imposible sostener que una interpretación del derecho debe basarse solamente en principios o deberes. Así lo establece Farrell, para quien si bien el sistema jurídico exige que el juez decida en base a principios, el consecuencialismo juega un rol importante en la decisión judicial en las siguientes situaciones:

La primera de esas dos situaciones aparece en casos de conflicto de derechos de igual jerarquía. En esos casos, el juez debe decidir cuál de los derechos prevalece aplicando un razonamiento consecuencialista. Prevalece aquel derecho cuyo respeto produzca las mejores consecuencias.

La segunda de las situaciones aparece en casos en los cuales el respeto de un derecho provocaría trágicas consecuencias. En estos casos -excepcionales por ciertoprevalecen directamente las consideraciones de utilidad $^{36}$.

De este modo, el cálculo de las consecuencias de la decisión que se tomará luego de interpretar el derecho puede tener un espacio importante que no es nada desdeñable por cuanto en la Constitución

${ }^{36}$ FARRELL, Martín, La ética de la función judicial, 2003, p. 161. 
Nacional -por citar un caso a título de ejemplo- hay un gran número de derechos que tienen la misma jerarquía y, como diría Apel, luego de la era atómica se ha comprendido que las consecuencias de la acción nunca son desdeñables y resulta absurdo pensar que podemos obrar solamente regidos por principios y sin importar las consecuencias que nuestra acción tendrá sobre el mundo.

Quizás una de las derivaciones del utilitarismo que mayor articulación de consecuencias y principios permita sea el utilitarismo de la regla, que exige que al tomar una decisión basada en el cálculo de la utilidad social tengamos en cuenta como un factor más el efecto que el quebrantamiento de una regla puede tener en el futuro.

En cuanto al método de enseñanza que se deriva de esta concepción del derecho, podemos avizorar que un alumno deberá ser capaz de calcular las pérdidas y beneficios que puede ocasionar un curso u otro de acción o una u otra decisión. En definitiva, es un método orientado hacia el futuro por cuanto no se trata de indagar voluntades o costumbres sino de establecer cuáles serían las consecuencias más beneficiosas en términos de utilidad social de las diversas interpretaciones posibles de las normas.

Ese cálculo de utilidad requiere de estrategias de enseñanza que fomenten la aplicación de métodos cuantitativos dirigidos no ya a la interpretación sino a la anticipación de resultados a través del establecimiento de relaciones entre variables. Más allá de la asimetría que la epistemología claramente asigna al par explicación-predicción, la didáctica del derecho aquí se propone describir, explicar y predecir el grado de satisfacción o insatisfacción que provocará en determinada población el seguimiento de una regla u otra o la interpretación de una norma u otra.

\section{Realismo}

El realismo es un tipo histórico que surgió en Estados Unidos aunque sus orígenes pueden rastrearse en ciertas corrientes europeas y tiene importantes ramificaciones en el ámbito escandinavo. Si bien desde fines del siglo XIX muchos autores advierten que el uso dogmático de los métodos puede llevar a injusticias evidentes, el realismo se torna cada vez más fuerte a partir de la década del 30 del Siglo XX. En los países del common law, los jueces tienen un amplio margen de libertad en la aplicación de aquellas reglas que surjan de los precedentes jurisprudenciales. Ante un marcado formalismo de los métodos, el realismo supone una focalización sobre la actividad de los jueces, a quienes considera los creadores del derecho.

Las corrientes realistas conciben así al derecho como un hecho, una conducta, un tipo particular de experiencia creada por los jueces. En tanto creación jurisprudencial, el derecho se puede derivar y hasta prever haciendo un estudio de los factores que influyen sobre las decisiones que toman los jueces.

Si se toma como punto de partida que el derecho es lo que dicen los jueces, los realistas suelen considerar que esos dichos poco tienen que ver con el seguimiento de los pasos de un método riguroso y sí en cambio están relacionados con ciertas preferencias o prejuicios que guían la decisión que a la postre se fundamentará jurídicamente. Dice Cueto Rúa refiriéndose a uno de los exponentes más radicales del realismo, Jerome Frank:

El derecho es comportamiento judicial. Es lo que los jueces deciden en los casos concretos. Los 
abogados deben procurar la predicción de ese comportamiento. Pero no se trata de anticipar, en lo medida de lo posible, cómo interpretarán las normas ni cómo declararán el derecho aplicable a cada caso, sino de algo mucho más difícil e incierto. Se trata de predecir su actitud ante la prueba y su mérito, y, en su virtud, cuál será la decisión del juez respecto de los 'hechos' del caso ${ }^{37}$.

Desde esta perspectiva, la doctrina jurídica se ha preocupado demasiado por la interpretación de las normas y ha descuidado aquello que origina la mayoría de los pleitos: el desacuerdo no en torno a las normas aplicables sino a la interpretación de los hechos. Al respecto dice Calamandrei: "Ex facto oritur ius (del hecho surge el derecho) es un viejo aforismo, cauto y honesto, que supone en quien desea juzgar bien, determinar, ante todo, con fidelidad minuciosa, los hechos discutidos. Pero ciertos abogados lo entienden al revés; una vez que han excogitado una brillante teoría jurídica que se presta a virtuosismos de fácil ingenio, ajustan a ella exactamente los hechos, que va siguiendo las exigencias de la teoría; y así ex iure oritur factum (del derecho surge el hecho)". ${ }^{38}$

Los hechos son pues el centro de una disputa judicial y el derecho mismo que surge en boca de los jueces para solucionar esa disputa es un hecho. El método de interpretación apunta a esos hechos y es un acto creador que en las versiones más radicales del realismo es de una gran autonomía. Más allá de las posibilidades que este acto creador da a los jueces de imponer sus prejuicios por encima de lo normado, la ética judicial que surge de estas posiciones entronca con el utilitarismo en el sentido de que el juez deberá predecir las posibles consecuencias de su obrar y decidir aquello que se acomode mejor a ciertos criterios de utilidad social.

Cuando los realistas piensan la educación legal dirigida a abogados no dudan que la más adecuada es aquella que les permita predecir lo que los jueces decidirán, porque eso es el derecho. ${ }^{39} \mathrm{Y}$ al menos en una concepción positivista clásica, la operación que debemos realizar para predecir es explicar; esto significa encontrar las razones por las cuales un juez decidió en un sentido en el pasado.

Así, por ejemplo, si descubrimos que un juez o un tribunal deciden las cuestiones de familia guiado por criterios religiosos, podremos predecir que en el futuro seguirá haciéndolo. Si trasladamos este método de enseñanza a los ciudadanos es factible establecer que la educación se dirigirá también a conocer las decisiones de los jueces para de esa manera predecirla. Para llevar a cabo esa predicción será importante el conocimiento que provenga de las ciencias sociales, en tanto nos permitirá determinar los factores psicológicos, económicos y culturales que influyen sobre la decisión de los jueces. Es sin duda una concepción muy particular del derecho, en tanto todo lo que podemos hacer es predecir conductas pero el derecho pierde toda capacidad de operar más allá de la "cultura judicial" en la que están inmersos esos jueces.

${ }^{37}$ CUETO RÚA, Julio, "Prólogo", 1993, p. 13.

${ }^{38}$ CALAMANDREI, Piero, Elogio de los jueces, 1995, p. 120.

${ }^{39}$ Decía Genaro Carrió, poniéndose en la piel de un abogado que se inicia en la práctica profesional: "Aprendemos una disciplina de tipo formal y, luego, vamos hacia la realidad empuñando herramientas ineficaces. Los primeros contactos con ella son desalentadores. Empezamos a elaborar, entonces, por debajo de la disciplina aprendida, una especie de técnica empírica con la que a la larga aprendemos a movernos en un medio donde la generalidad se mueve así, lo que nos permite salir del paso. La que no sale bien parada es la sociedad, cuyos problemas quedan sin resolver. Se va creando así un estado de insatisfacción respecto de la Ciencia del Derecho. Pagamos tributo verbal a las enseñanzas recibidas y a la Ciencia en cuyo nombre fueron impartidas. Pero en la práctica hacemos otra cosa. El prestigio de la ciencia nos intimida y no nos atrevemos a echarle la culpa; preferimos echársela a los hechos, en cuya indocilidad vemos el origen de nuestras tribulaciones". CARRIÓ, Genaro, "Sobre las creencias de los juristas y la ciencia del derecho", 2003, p. 124-125 
El método de casos, basado en fallos judiciales, es la primera fuente que permite conocer cómo deciden los jueces, en base a qué criterios y de ese modo se pueden anticipar las interpretaciones futuras. El método de casos "consiste en la discusión en clase de casos (en el sentido de fallos jurídicos) previamente leídos y trabajados por los estudiantes fuera del horario de clase. Se combina con el 'método socrático', en tanto el docente formula durante la clase a los alumnos diversas preguntas sobre los hechos del caso, la fundamentación y la decisión que contiene la sentencia, las otras posibles soluciones, etc. Es decir, gira en torno a un diálogo entre el docente y los alumnos y una enseñanza por medio de la pregunta, el parafraseo, la re-pregunta". ${ }^{40}$

El caso judicial ocupa aquí el centro de la escena, es el punto te contacto entre alumnos y docente aunque, como lo han apuntado muchos de los críticos de esta estrategia, este último muchas veces asume una posición central en cuanto distribuye la palabra, elige a quién preguntar y repreguntar y, en ocasiones, tiene la última palabra.

\section{Sistemática}

A partir de los postulados generales del positivismo, este tipo considera al derecho como un sistema normativo jerárquico y sistemático, en el cual cada norma se relaciona con un conjunto dentro del cual encuentra su sentido preciso. Así es porque el legislador no obra arbitrariamente, sino que sus prescripciones obedecen a un orden que impide que una norma se interprete en forma aislada. En efecto, el sentido de una norma no está dado por los términos que la expresan, sus motivos o sus consecuencias, sino por su relación con otras normas con las cuales conforma un sistema armonioso. Si bien hay normas generales que orientan todo el ordenamiento, las normas se agrupan en conjuntos parciales que pueden estar formados por las que pertenecen a una rama del derecho (civil, penal, tributario, comercial, etc.) o por las que rigen una institución, como la familia, los contratos, la aeronavegación, etc. A partir de la segunda mitad del siglo XIX, la dogmática jurídica emprendió la tarea de elaborar categorías sistemáticas que le permitieran reconstruir teóricamente el derecho positivo. La interpretación sistemática se elabora sobre esas construcciones dogmáticas: sus procedimientos son básicamente la definición y esclarecimiento de conceptos, la determinación de sus relaciones lógicas, el establecimiento de un lenguaje técnico especial.

El objeto de interpretación es determinar el sentido de la norma, contextualizándola en el sistema normativo. Desde luego esta labor requiere un conocimiento muy profundo de la estructura de ese ordenamiento y esto requiere especialistas capaces de analizar lógicamente la pirámide normativa y para ello es preciso que conozcan las construcciones dogmáticas que la sostienen.

La estrategia de enseñanza más pertinente es aquí la clase magistral aunque el profesor, a diferencia del correspondiente a la concepción exegética, no enuncia la norma sino que ubica esa norma dentro del plexo normativo y les da sentido a través de las instituciones que dan cuenta de cada rama del derecho. Sólo un especialista puede ocupar ese rol. La currícula de colección se adapta perfectamente a esta concepción del derecho por cuanto cada asignatura se cierra sobre sí misma y sus correspondientes instituciones.

${ }^{40}$ CLÉRICO, Laura, "Notas sobre los libros de 'casos' reconsiderados en el contexto del 'método de casos"”, 2003 , p.18. 


\section{Análisis crítico}

Este tipo conceptualiza al derecho como un conjunto de prácticas políticas reproductoras del statu quo. Esas prácticas no tienen por objeto contribuir al bien común sino ejercer un fuerte control social que impida que aquellos que no han sido favorecidos por el reparto de riquezas sean disciplinados y, en lo posible, adhieran al sistema creyendo que si otros tienen lo que ellos no han logrado es porque han hecho las cosas como debieron para lograr el éxito. Decía Merton, refiriéndose a la sociedad americana de los años cuarenta:

... la cultura impone la aceptación de tres axiomas culturales: primero, todos deben esforzarse hacia las mismas metas elevadas, ya que están a disposición de todos; segundo, el aparente fracaso del momento no es más que una estación de espera hacia el éxito definitivo; y tercero, el verdadero fracaso está en reducir la ambición o renunciar a ella. [...]... (E)stos axiomas representan, primero, la desviación de la crítica de la estructura social hacia uno mismo, entre los situados en la sociedad de manera que no tienen acceso pleno e igual a las oportunidades; segundo, la conservación de una estructura de poder social mediante la existencia en los estratos sociales más bajos de individuos que se identifican, no con sus iguales, sino con los individuos de la cumbre (a quienes acabarán uniéndose); y tercero, la actuación de presiones favorables a la conformidad con los dictados culturales de ambiciones irreprimibles mediante la amenaza para quienes no se acomoden a dichos dictados de no ser considerados plenamente pertenecientes a la sociedad ${ }^{41}$.

Merton se refiere a una sociedad en la que el grueso de su población mantiene la expectativa de ascenso social. Cuando esa expectativa se torna evidentemente inviable para grandes masas, es probable que el derecho se concentre en el disciplinamiento de quienes no se conforman con su situación a través de mecanismos represivos. Ya sean más blandos o más duros, los controles son administrados por el derecho, que los despoja ficticiamente del carácter ideológico que tienen. A partir de este diagnóstico, el método de interpretación que el análisis crítico se propone apunta a denunciar las estrategias de dominación encubiertas en la legislación y explotar estratégicamente los recursos disponibles en ella.

De acuerdo a Correas, la crítica jurídica tiene como principal tarea desenmascarar la eficacia del derecho:

Lo que constituye la preocupación fundamental, una vez aceptado y comprendido que el derecho es una técnica de control social, es la manera cómo, en esta sociedad, la capitalista, el discurso jurídico es eficaz; esto es, cómo efectivamente consigue la dominación de los sectores no favorecidos de la sociedad por parte de los grupos en el poder ${ }^{42}$.

La enseñanza crítica del derecho ha de procurar el reconocimiento de la base ideológica del derecho y el fortalecimiento de destrezas que habiliten un incremento del acceso a la justicia. Esta última función solamente es viable en versiones críticas que otorgan al derecho alguna posibilidad de constituirse en un instrumento de cambio social favorable a la mayoría de la población o a quienes están en peor situación socio-económica. En versiones críticas más radicales, la única función éticamente correcta de la enseñanza del derecho sería la concientización de los alumnos acerca de la necesidad o utilidad

${ }^{41}$ MERTON, Robert, Teoría y estructura sociales, 1984, p. 217.

${ }^{42}$ CORREAS, Óscar, Sociología del derecho y crítica jurídica, 1988, p. 99. 
de liberarse de la explotación legitimada jurídicamente.

Una de las escuelas críticas, la de los Critical Legal Studies,

lo que pretenden es politizar la enseñanza del Derecho. Por politizar entendemos no adoctrinar sino, de cierta forma contextualizar al Derecho. Se trata de desnudar al Derecho de su falsa pretensión de neutralidad valorativa y contemplar los debates morales, políticos y filosóficos que lo conforman y de los que forma parte. Se busca explicitar los contenidos morales y políticos y los puntos de partida filosóficos que configuran el discurso jurídico, por una parte, y desactivar las limitantes que esconden estos elementos bajo un formalismo con pretensión de neutralidad ${ }^{43}$.

Esta tarea de concientización requiere una reconstrucción de las condiciones de creación y aplicación del derecho, a través de una indagación histórica y social (sociológica, económica, antropológica) que por supuesto incluye a la reproducción del derecho a través de su enseñanza. ${ }^{44}$ En esta tarea el profesor guía el proceso a través del cual los alumnos conocen la base ideológica del derecho, los intereses que protege y, si es posible, desarrollan las destrezas necesarias para aprovechar los intersticios que el derecho deja para el reconocimiento y provisión de derechos de las minorías, los pobres, los excluidos. En este último caso, la estrategia de enseñanza es posible que se combine con la prevalente en el tipo que desarrollaremos a continuación.

\section{Deliberativismo}

Este tipo, cuya construcción es plenamente conceptual por cuanto no hay un período histórico en el que prime, concibe al derecho como un conjunto de prácticas sociales moralmente legitimadas ${ }^{45}$ a través de un proceso de deliberación pública que respeta ciertos derechos fundamentales. Estos derechos son previos a la deliberación y por ende no están sujetos a lo que de ella resulte.

Así, las normas positivas solamente son legítimas en la medida en que respeten ciertas reglas de procedimiento, que comprenden el respeto de derechos fundamentales y la participación de todos los posibles afectados por las normas en la deliberación ${ }^{46}$.

\footnotetext{
${ }^{43}$ MADRAZO LAJOUS, Alejandro, “¿Qué?, ¿Cómo? Y ¿Para qué? Análisis y crítica al modelo tradicional de enseñanza del derecho en México", 2006, p. 225

${ }^{44}$ Dice Duncan Kennedy: "Decir que las facultades de derecho son ideológicas significa decir que lo que los profesores enseñan junto con los conocimientos básicos está mal; que lo que se enseña sobre cómo es el derecho y cuál es su funcionamiento no tiene sentido; que los mensajes sobre la naturaleza de las destrezas jurídicas y de su distribución entre los estudiantes son erróneas y tampoco tienen sentido; que las ideas que reciben los estudiantes acerca de las posibilidades de la vida como abogado también están equivocadas y son absurdas. Pero toda esa serie de sinsentidos está orientada, tiene un sesgo concreto y motivado, no es un error casual. Lo que pretende inculcar es que es natural, eficiente y justo que los estudios jurídicos, la profesión de abogado en general, y la sociedad a la que los abogados prestan sus servicios estén organizados de acuerdo a los patrones de jerarquía y dominación”. KENNEDY, Duncan, “La educación legal como preparación para la jerarquía”, 2003 , p. 117.

45 Dice Nino con respecto a la justificación moral del sistema jurídico: “... es la función de hacer efectivos los derechos individuales básicos lo que provee la justificación moral primaria de la existencia de un orden jurídico establecido, o sea de un gobierno establecido". Ver: NINO, Carlos Santiago, Ética y derechos humanos, 1984, p. 226.

${ }^{46}$ Dice Habermas al referirse a la necesidad de legitimar moralmente las normas: "La legalidad sólo puede engendrar legitimidad en la medida en que el orden jurídico reaccione reflexivamente a la necesidad de fundamentación surgida con la positivización del derecho, y ello de suerte que se institucionalicen procedimientos jurídicos de fundamentación que sean permeables a discursos morales”. Ver, HABERMAS, Jürgen, “Escritos
} 
El método de interpretación procura elaborar la mejor interpretación en orden a la protección de los procedimientos de deliberación pública tanto en la creación como en la interpretación del derecho. Se trata de posibilitar de este modo la plena vigencia de los procedimientos de debate público en la creación del derecho, cuya aplicación será controlada también por los ciudadanos. La enseñanza del derecho es un entrenamiento en las habilidades básicas de la deliberación, que balancea la moral ideal con los límites que la democracia real establezca. Dado que en el derecho anida un ideal de justicia que está plasmado en los derechos fundamentales, que en el caso actual pueden ser equiparados a los derechos humanos, la deliberación apunta a ese ideal pero sin olvidar que en una comunidad concreta muchas veces ese ideal debe compatibilizarse con ciertas necesidades que requieren apartarse de él. Al criticar la teoría de los dos reinos kantiana, Apel parte de la existencia de dos comunidades de comunicación, una ideal y otra real, anticipada contrafácticamente ${ }^{47}$, y los participantes pertenecen a ambas simultáneamente. De aquí surge una regla de esa deliberación: "la obligación, para una estrategia de largo plazo, de la (colaboración en la) transformación de las situaciones reales, con el fin de acercarse a las condiciones ideales de la solución discursiva-consensual de conflictos" ${ }^{28}$.

Las estrategias más pertinentes con respecto a esta concepción del derecho son un método de casos reformulado y el juego de roles. El primero no es asimilable al método de casos utilizado como estrategia principal en la concepción realista del derecho. Como sostiene Clérico, este método "se refiere al trabajo con casos hipotéticos o reales en los cuales los estudiantes se enfrentan al desafío de comprender el caso, de buscar una o varias soluciones, de analizarlas y ponderarlas, entre otras cosas" 49 ,

El juego de roles implica asumir una posición en una situación ficticia pero, también, en una real en el transcurso de la cual se produce un aprendizaje. Así, por ejemplo, Goldbarb reflexiona acerca de las posibilidades que una clínica jurídica brinda para el desarrollo de una concepción crítica que podemos aquí solapar con una concepción deliberitivista: "Una clínica puede darle al crítico un lugar donde situarse dentro de la pedagogía de una escuela de Derecho. Implica ponerse en el lugar de una persona con necesidades, alguien cuyas necesidades pueden ser productos de la intersección del sistema legal con las estructuras de la pobreza, la raza y otros sistemas de castas de nuestra cultura. El pensamiento crítico que puede surgir del proceso clínico - de la interacción dinámica entre el profesor, el alumno, el cliente y otros actores de la burocracia legal- tiene una existencia física que puede ser (....) significativa" 50 .

\section{A modo de cierre}

A lo largo de este trabajo, he comenzado por reseñar las principales confluencias de las investigaciones empíricas que se han desarrollado en la Argentina sobre enseñanza universitaria del derecho, iluminándolas con algunas líneas teóricas que nos permiten avizorar que las principales aristas de los procesos de enseñanza y aprendizaje del derecho reconocen similitudes con otros momentos históricos y también con lo que sucede en otros sistemas universitarios del mundo.

sobre moralidad y eticidad", Paidós, Barcelona, 1991, p. 163.

${ }^{47}$ APEL, Karl-Otto, Teoría de la verdad y ética del discurso, 1991.

${ }^{48}$ APEL, Karl-Otto, "La solución de conflictos en la era atómica como problema de una ética de la responsabilidad", 1988.

${ }^{49}$ CLÉRICO, Laura, "Notas sobre los libros de 'casos' reconsiderados en el contexto del 'método de casos', p. 18.

${ }^{50}$ GOLDFARB, Phyllis, "Escogiendo la ley”, 2008, p. 23 
En otro nivel de análisis, y a partir de una hipótesis que relaciona -en sus extremos- las concepciones del derecho con las estrategias montadas para su enseñanza, generé una tipología que acaso pueda resultar útil para que sigamos pensando estas categorías y también para ensayar otras estrategias de enseñanza que nutran aquella concepción del derecho de la que partamos.

Así, con lo anterior se entiende que si queremos trascender el diagnóstico acerca de cómo se enseña derecho en nuestras facultades y escuelas de derecho (en el que parece que hemos confluido en puntos importantes), tal vez el próximo paso sea interrogar qué grado de permeabilidad tienen los profesionales jurídicos formados en base a distintas estrategias didácticas con respecto a las demandas de reconocimiento y provisión de derechos. Lo que sucede al interior de los muros de las aulas de derecho es reflejo o razón de los déficits que el derecho presenta a la hora de dar respuesta a dichas demandas. Hacernos cargo de ellas no es una tarea de "extensión", de ligazón de la universidad con su medio o algo que esperamos que suceda una vez que los alumnos se conviertan en abogados, funcionarios, jueces, sino que es una tarea que implica al proceso de enseñanza, lo define, lo compromete.

\section{Referencias bibliográficas}

ALEXY, Robert . Teoría del discurso y derechos humanos (trad. Luis Villar Borda), 2a ed, Bogotá: Universidad Externado de Colombia, 1995, 136 pp.

APEL, Karl-Otto. Teoría de la verdad y ética del discurso (trad.Norberto Smilg), $1^{\text {a }}$ edición, Barcelona: Gedisa, 1991, 192 pp.

APEL, Karl-Otto. "La solución de conflictos en la era atómica como problema de una ética de la responsabilidad", Cuadernos de Ética, N 5, junio de 1988, Buenos Aires: Asociación Argentina de Investigaciones Éticas, pp. 7-24.

BECCARIA, Cesare. De los delitos y las penas, (trad. Juan Antonio de las Casas), Barcelona: Altaya, 1994, 206 pp.

BENEITON, Pablo et. al. Reflexiones y perspectivas de la educación superior en América latina. Informe final Proyecto Tuning América Latina 2004-2007, Bilbao: Publicaciones de la Universidad de Deusto y la Universidad de Groningen, 2007, 432 pp.

BERGOGLIO, María Inés y CARBALLO, Jerónimo, “Segmentación en la profesión jurídica: cambios ocupacionales de los abogados argentinos. 1995-2003", en Academia, Revista sobre enseñanza del derecho de Buenos Aires, Buenos Aires: Departamento de Publicaciones de la Facultad de Derecho de la Universidad de Buenos Aires, Año 3, Número 5, 2005, pp. 201-222.

BÖHMER, Martín "Algunas sugerencias para escapar del silencio del aula”, en Academia, Revista sobre enseñanza del derecho de Buenos Aires, Buenos Aires: Departamento de Publicaciones de la Facultad de Derecho de la Universidad de Buenos Aires, Año 1, Nº1, 2003, pp. 13-34. 
BULLARD, Alfredo y MAC LEAN, Ana, “La enseñanza del derecho: ¿cofradía o archicofradía?”, en Academia, Revista sobre enseñanza del derecho, Buenos Aires: Departamento de Publicaciones de la Facultad de Derecho de la Universidad de Buenos Aires, Año 7, No 13, 2009, pp. 21-47.

CALAMANDREI, Piero. Elogio de los jueces, Tribunal, México, 1995, 284 pp.

CAPPELLETTI, Graciela. "La evaluación por competencias", en ANIJOVICH, Rebeca (comp.) La evaluación significativa, Buenos Aires: Paidós, 2010, pp. 177-206.

CARDINAUX, Nancy et. al. De cursos y de formaciones docentes, Buenos Aires: Departamento de Publicaciones de la Facultad de Derecho de la Universidad de Buenos Aires, 2005, 168 pp.

CARRIÓ, Genaro, "Sobre las creencias de los juristas y la ciencia del derecho". Academia, Revista sobre enseñanza del derecho de Buenos Aires, Buenos Aires: Departamento de Publicaciones de la Facultad de Derecho de la Universidad de Buenos Aires, Año 1, No2, ( publicado originalmente en Lecciones y Ensayos, 1957), 2003, pp. 111-126.

CLÉRICO, Laura. "Notas sobre los libros de 'casos' reconsiderados en el contexto del 'método de casos'. Academia, Revista sobre enseñanza del derecho de Buenos Aires, 2003, Año $1 \mathrm{~N}^{\mathbf{0}}$ 2, Buenos Aires: Departamento de Publicaciones de la Facultad de Derecho de la Universidad de Buenos Aires, pp. 13-41.

COLMO, Alfredo. "Sobre didáctica del Derecho Civil. Principios y espíritu del nuevo Programa de Derecho Civil, en Academia, Revista sobre enseñanza del derecho, 2011, Año 9, Número 17, Buenos Aires: Departamento de Publicaciones de la Facultad de Derecho de la Universidad de Buenos Aires, pp. 115-145.

CORREAS, Óscar. Sociología del derecho y crítica jurídica, Fontamara, México, 1988, 224 pp.

CORNU, Laurence. "La confianza en las relaciones pedagógicas", en FRIGERIO, Graciela et.al., Construyendo un saber sobre el interior de la escuela, Buenos Aires: Novedades Educativas, 2007, 192 pp.

CUETO RÚA, Julio, "Prólogo" en FRANK, Jerome, Derecho e incertidumbre, (trad. Carlos Bidegain) Fontamara, México, 1993 (publicado originalmente en New York University Law Review, 1951), 143 pp.

Facultad de Ciencias Jurídicas y Sociales, UNLP, Diagnóstico e ideas preliminares para la modificación del plan de estudios de la FCJyS de la UNLP, documento interno, La Plata, 2002.

FARRELL, Martín. "La ética de la función judicial”, en MALEM, Jorge et.al. (comps) La función judicial. Ética y democracia, Barcelona: Gedisa, 2003. 317 pp.

GOETHE, Johann Wolfgang. Fausto. (trad. José Roviralta Borrell), 2ª reimp., Madrid: Alianza, 2006, 504 pp.

GOLDFARB, Phyllis, "Una espiral entre la teoría y la práctica. La ética del feminismo y la educación práctica", en Academia, Revista sobre enseñanza del derecho de Buenos Aires, Buenos Aires: Departamento de Publicaciones de la Facultad de Derecho de la Universidad de Buenos Aires, Año 3, N 6, 2005, pp. 67-156.

GOLDFARB, Phyllis. "Escogiendo la ley", en Academia, Revista sobre enseñanza del derecho, Buenos Aires: Departamento de Publicaciones de la Facultad de Derecho de la Universidad de Buenos Aires, Año 6, No11, 2008, pp. 9-28. 
GONZÁLEZ, Manuela et.al. "La formación de los abogados y la formación jurídica en Argentina”, en GONZÁLEZ, Manuela y LISTA, Carlos (coords.), Sociología Jurídica en Argentina: tendencias y perspectivas, $1^{\text {a }}$ edición, Buenos Aires: Eudeba, 2011, pp. 279-334.

GONZÁLEZ, Manuela y CARDINAUX, Nancy (comps.) Los actores y las prácticas. Enseñar y aprender derecho en la UNLP, La Plata: Editorial de la Universidad Nacional de La Plata, 288 pp.

HABERMAS, Jürgen. Facticidad y validez. Sobre el derecho y el Estado democrático de derecho en términos de teoría del discurso (trad. Manuel Jiménez Redondo), $1^{\text {a }}$ edición, Madrid: Trotta, 2001, 696 pp.

KENNEDY, Duncan, "La educación legal como preparación para la jerarquía”, en Academia, Revista sobre enseñanza del derecho de Buenos Aires, Buenos Aires: Departamento de Publicaciones de la Facultad de Derecho de la Universidad de Buenos Aires, Año 2, No3, 2003, pp. 117-147.

LANDI, Oscar. Reconstrucciones. Las nuevas formas de la cultura política, Buenos Aires: Puntosur, 1988, $212 \mathrm{pp}$.

LISTA, Carlos y BEGALA, Silvana. "Los resultados de una socialización exitosa: la reproducción del modelo jurídico dominante", en BRÍGIDO, Ana María et al. (coords.) Crónica de una metamorfosis, Córdoba: Hispania, 2009, 216 pp.

LLEWELLYN, Karl. "El derecho y las ciencias sociales, especialmente la sociología", Academia, Revista sobre enseñanza del derecho de Buenos Aires, Buenos Aires: Departamento de Publicaciones de la Facultad de Derecho de la Universidad de Buenos Aires, Año 1, №1, 2003 (originalmente publicado en 1949 por la Harvard Law Review) pp. 99-119.

MADRAZO LAJOUS, Alejandro. “¿Qué?, ¿Cómo? Y ¿Para qué? Análisis y crítica al modelo tradicional de enseñanza del derecho en México". Academia, Revista sobre enseñanza del derecho de Buenos Aires, Buenos Aires: Departamento de Publicaciones de la Facultad de Derecho de la Universidad de Buenos Aires, Año 4, Nº7, 2006, pp. 167-247.

MERTON, Robert. Teoría y estructura sociales. (trad. Florentino M. Torner y Rufina Borques), $2^{\mathrm{a}}$ edición, México: Fondo de Cultura Económica, 1984, 741 pp.

NINO, Carlos Santiago. Ética y derechos humanos, $1^{a}$ edición, Buenos Aires: Paidós, 1984, 304 pp.

PÉREZ LLEDÓ, Juan Antonio. “Teoría y práctica en la enseñanza del Derecho”, Academia, Revista sobre enseñanza del derecho, Buenos Aires: Departamento de Publicaciones de la Facultad de Derecho de la Universidad de Buenos Aires, Año 5, Nº, 2007, pp. 85-189.

RUIZ, Guillermo. "La educación por competencias: definiciones y alcances de su aplicación en la formación judicial", mimeo en prensa.

SOUSA SANTOS, Boaventura de. La universidad en el Siglo XXI. Para una reforma democrática y emancipadora de la universidad. Buenos Aires: Miño y Dávila, 2007, 86 pp.

VERNENGO, Roberto. Curso de teoría general del derecho. $1^{a}$ ed., Buenos Aires: Cooperadora de Derecho y Ciencias Sociales, 1976, 461 pp. 